\title{
AGILITY IN FOURS: IT Diffusion, IT Infrastructures, IT Development, and Business
}

\author{
Richard L. Baskerville \\ Georgia State University \\ Atlanta, GA U.S.A. \\ Lars Mathiassen \\ Georgia State University \\ Atlanta, GA U.S.A. \\ Jan Pries-Heje \\ IT University of Copenhagen \\ Copenhagen, Denmark
}

\begin{abstract}
Business agility is a relatively new paradigm painted as a solution for maintaining competitive advantage during times of uncertainty and turbulence in the business environment (Sharifi and Zhang 2001). Agility is a concept that extends adaptability and flexibility to include speed and scalability. Agile organizations are not only capable of change, but they are nimble, capable of changing quickly and gracefully. The concept of agility arose first from flexible manufacturing (Kidd 1995), and has been quickly adopted by organizations producing software in the form of agile software development (Aoyama 1998; Cockburn 2001).

It seems patently obvious that organizational information technology plays a crucial role in shaping business agility. The ability to quickly change the type and flow of information within an organization must underlie a rapid and graceful reorganization. But there is a fundamental gap between the IT function and the rest of the organization. This gap, called the IT paradox, is a setting in which top management sees the value of an effective IT operation and infrastructure, but lacks a real understanding of how IT essentially contributes to business value (Morgan 2004).

This IT paradox has grown more critical in the wake of frenzied spending on IT driven by the $\mathrm{Y} 2 \mathrm{~K}$ and dot-com imperatives. The subsequent economic downturn drove a widespread, fundamental reexamination of organizational investments in information
\end{abstract}


technology. During periods of economic growth, organizations may drive forward IT projects with some disregard for how these align with the rest of the organizational IT portfolio. In such a period the IT paradox was less of a problem. In the subsequent downturn, however, organizations reflect on the unbalanced IT infrastructure that emerges from the disregarded portfolio. During this latter period, the focus of many projects is on stabilizing the IT infrastructure rather than developing new competitive advantage. As a result, organizations are balancing their IT spending, seeking to become better positioned (i.e., more agile) in preparation for the next economic expansion (Leidner, Beatty, and Mackay 2003). Not surprisingly, the globalization of the IT workforce is one aspect of this economic and infrastructure repositioning (Hoffman 2003).

The purpose of this book is to improve our knowledge of how IT can enable business agility and thereby help close the gap of knowledge that defines the IT paradox. This is a timely purpose as organizations rebalance their IT infrastructure and portfolio of IT innovations in preparation for the next economic expansion.

The book is organized along the plan illustrated in Figure 1. We explore the issues, concepts, motives, factors, techniques, and challenges of developing business agility with IT in six major sections. First, we set the stage for exploring business agility and its relationship to IT diffusion by asking the question: Why agility now? Second, we approach the relationship by exploring its four most distinct parts: (1) agile IT diffusion, (2) IT infrastructures agility, (3) agile development, and, at the core, (4) business agility. Finally, we look at some of the challenges that confront us ahead.

\section{Why Agility?}

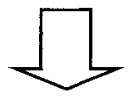

2. Agile IT Diffusion

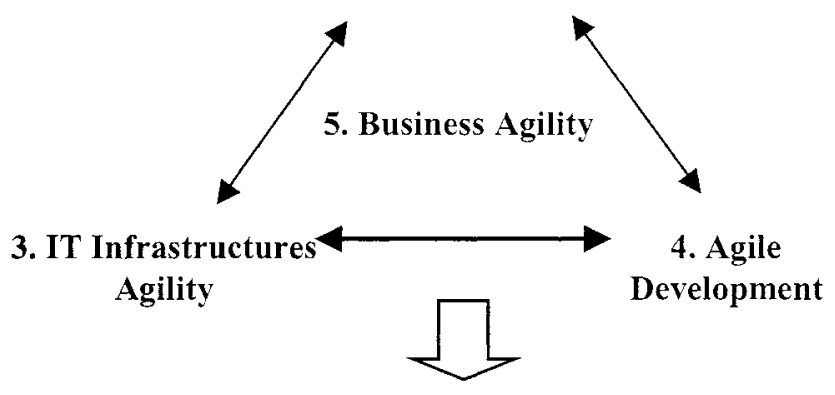

6. Challenges Ahead

Figure 1. Plan For The Book 


\section{WHY AGILITY NOW?}

Part 1 sets the stage. Chapter $I$ introduces the topic and provides an overview of the research contributions that are included in this book.

We ask, "Why agility now?" We believe there are at least three answers. First, it continues to become harder to survive and succeed in today's business environment. Being agile, and being capable of sensing and responding to both predictable and unpredictable events is a promising strategy in times of change and uncertainty. There is a lot of recent activity about agility, promoted in the form of agile software development, agile manufacturing, agile modeling, and agile iterations. Second, IT diffusion is known to be a process that takes time and effort. Numerous IT projects succeed in developing a product, but fail in changing the behavior of the target group. As a result, diffusion just doesn't happen! It is hardly surprising that agile IT diffusion has become desirable. Third, the importance of flexibility in developing IT solutions for rapidly changing business environments is well recognized, especially for Internet applications (Pries-Heje et al. 2004). In this arena, agility refers to the ability to quickly deliver solutions and nimbly adapt to changing requirements.

Chapter 2, by Kautz, Henriksen, Breer-Mortensen, and Poulsen provides an introspective for the group that has commissioned this book as the proceedings from a conference by the International Federation for Information Processing Working Group 8.6. This group focuses on the diffusion of IT innovations. Chapter 2 provides an overview of the essential concepts and background that this working group brings to our question. It includes a detailed analysis of all previous IFIP Working Group 8.6 conference proceedings, and concludes that the group has been successful thus far in focusing scholarly attention on the phenomenon within its scope, and marshaling intellectual progress toward its objectives.

Chapter 3 introduces agility concepts and their relationship with agile software methods. Conboy, Fitzgerald, and Golden provide an overview and synthesis of agility concepts, applying these insights to propose a framework for agile software methods. The framework distinguishes between required resources and resulting impact, presenting on that basis four different categories of agile practices: change creation, action, reaction, and learning.

The next four parts comprise the heart of the book, describing the factors and techniques that lead organizations to business agility. From the perspective of our working group, business agility depends on the intrinsic and dynamic relationships between IT diffusion, IT infrastructure, and IT development capabilities (see Figure 1). We start by reviewing each of these IT-related capabilities and finally develop the core theme of business agility.

\section{AGILE IT DIFFUSION}

Part 2 explores the complex relationship between IT diffusion and business agility. Diffusion of innovations, and in particular diffusion of new approaches to the development of IT or software, constantly reshapes organizational IT capabilities. This part explores two aspects of the creation of business agility through IT diffusion. First, 
chapters 4,5 , and 6 help explain why efforts to improve software practices succeed (or fail to succeed). Chapter 4 uncovers how collaborative practices are associated with process deployment. Chapter 5 connects software process improvement and business agility by showing how choke points in the social communication networks can inhibit software innovation and, as a consequence, business agility. In Chapter 6, we extend our exploration of these social networks into those supporting interorganizational adoption of software innovations, learning how these social networks enable the creation and sharing of the knowledge essential for adoption of new software innovations. Second, chapters 7 and 8 provide techniques for enabling the innovation diffusion on which business agility depends. The two chapters bring focus on the role of the change agent, how to time the enrollment of a change agent, and how the shortcomings of a change agent can be overcome socially, exemplified by personal humor.

Chapter 4 by Aaen, Böjesson, and Mathiassen analyzes 18 software process improvement projects according to characteristics like set up, process creation and diffusion, and navigability. Eleven of the less successful projects focus on defining a solution but not on deploying a process. Seven of the more successful projects focus on collaboration as a means of simultaneously defining and deploying practices.

Chapter 5 by Nielsen and Tjørnehøj demonstrates how social network mapping can reveal communication choke points that can inhibit both agile business responses and software process improvement initiatives.

In Chapter 6, Hovorka and Larsen discuss how knowledge flows affected the adoption of a large-scale software system in several counties within New York state. They find that an organization's agility is based on its ability to acquire, assimilate, transform, and exploit knowledge, and that this ability can be increased through strong and dense networks. They also examine how social communication networks can influence the agility of organizations. For example, they find that having strong and dense communication networks can facilitate knowledge flows and increase the chance of adoption.

Chapter 7 by Börjesson, Martinsson, and Timmerås describes an action research study of diffusion of innovation techniques as a means for implementing software process improvement. The paper provides a particularly rich explanation of how change agents can co-opt key opinion leaders at a critical juncture (the chasm) in order to achieve a precipitous diffusion of a process innovation.

Chapter 8 by McMaster, Wastell, and Henriksen examines the role of humor as an empowerment tool. The concept of humor in organizations is clearly an underresearched area. This paper compares the role of a jester with that of a change agent and finds that a jester has characteristics lacking in a change agent. They conclude that there is a cathartic role for a jester in agile IT diffusion.

\section{IT INFRASTRUCTURES AGILITY}

Part 3 explores the relationship between the agility in IT infrastructures and the agility in business. IT infrastructures can both enable and inhibit business agility, perhaps even simultaneously. We begin in Chapter 9, showing the dramatic impact that a change in infrastructure can have on organizational performance by enabling agile 
decision-making. Chapters 10 and 11 explain how the infrastructures involved in interorganizational systems and supply chains are related to either business agility or business torpidity.

In Chapter 9, Vance reports the results of a lab experiment involving better and timelier information. Simulating supply chain decision-making, the experiment shows how remarkable improvements in financial performance can follow from agile business practices operating with better information technology, in this case simulating the addition of RFID as part of the information infrastructure.

In Chapter 10, Nagy applies the adoption position model to explain reasons for failure to adopt interorganizational systems in order to enable supply chain agility. Three cases are presented focusing on how the relative power between firms shapes adoption practices and outcomes

Chapter // by Holmqvist and Pessi presents lessons from a Volvo initiative to innovate and improve a global supply chain. The lessons are based on several years of continuous development, integrating legacy systems and new IT-infrastructure elements. These efforts led to new relations and channels that enabled unprecedented levels of business agility.

\section{AGILE DEVELOPMENT}

Part 4 explores the relationship between IT or software development and business agility. In this part of the book, we explore the factors upon which development agility depends, along with techniques for building it. Chapter 12 illustrates the unrecognized benefits that can follow from the adoption of agile development methods. We follow this with Chapter 13, which explains how software agility arises from innovations in both processes and base technology. Chapters 14 and 15 explore the practical limits of agile development, highlighting problems in specific agile techniques. This part concludes with Chapter 16, which models the strategic connection between agile IT development projects and business agility.

In Chapter 12, Fitzgerald and Hartnet present a longitudinal study of the use of agile software methods within Intel. The study demonstrates how agile methods lead to systematic practices that require disciplined application of the involved techniques as well as careful customization of the method to each specific development context.

In Chapter 13, Lyytinen and Rose outline a theory of agile development. In their model, exploration, exploitation, and agility issues are included, and a sequential learning model developed. The value of the model is illustrated with findings from software development organizations. The study concludes that software agility is affected by the scope and depth of innovative activity in base technologies as well as in continued process innovations.

In Chapter 14, Abrahamsson presents the results from a series of case studies in which test-driven software development was adopted. While test-driven development has been argued to facilitate agility and dramatic quality gains, this study shows that adoption of test-driven development is difficult and the potential benefits are far from readily available. 
Chapter 15 by Toleman, Darroch, and Ally describes experiences of developers in adopting eXtreme Programming in a low-budget setting. While the project was generally successful, insights suggest problems with system metaphors and pair programming

In Chapter 16, Nickolaisen describes a model that has proved effective in guiding resource allocation decisions for IT projects. The model positions strategies on two dimensions: the degree to which activities are mission-critical, and the degree to which activities provide market differentiation. It provides one example of how improved business agility results from smart use of this model.

\section{BUSINESS AGILITY}

Part 5 explores business agility, the core theme of the book, and the part around which all other parts revolve. Chapters 17 and 18 explore the factors that are driving organizations to seek agility, and also why this agility is unfolding in some arenas, and is not unfolding in others. In Chapter 19, we develop a framework for characterizing the differences in business agility among firms. Chapter 20 concludes this part of the book by explaining the essence of business agility with directions for seeking it.

In Chapter 17, Donnellan and Kelly describe the forces that drive increasing needs for business agility. They analyze the IT that is being developed to enable this agility in the semiconductor industry and show how this IT has diffused across the industry.

Chapter 18 by van Oosterhout, Waarts, and van Hillegersberg defines a framework and surveys four industry sectors in the Netherlands. The authors find a number of interesting differences among sectors. But they also find that executives across sectors feel that they are forced to become agile, for example due to increasing unpredictability of government regulation. Furthermore the study reveals that today's businesses lack the agility required to quickly respond to largely unanticipated changes.

Chapter 19 by Overby, Bharadwaj, and Sambamurthy presents a framework for business agility and the enabling role of digital options. Based on a distinction between sense and response capabilities the paper identifies four different types of firms: agile, languid-lazy, lost-leaping, and limited.

In Chapter 20, Dove discusses the cornerstones of business agility: response ability, dynamic knowledge management, and value-based decision making. The paper offers on that basis the requirements to design and develop agile business practices and IT infrastructure support.

\section{CHALLENGES AHEAD}

Part 6 concludes the work by recognizing some of the challenges that confront us in the quest to enable business agility with IT. Two chapters offer prospects for the future, cspecially highlighting the need to explore innovation in very large systems and the need for new work in IT or software development.

In Chapter 21, Dittrich, Pries-Heje, and Hjort-Madsen describe a large IT infrastructure and development project that is daring in both scope and innovation. It 
crystallizes broad gaps in the knowledge that ought to inform a large Federated organization seeking to migrate onto an entirely new IT infrastructure. Such gaps include the role of an IT vision, the feasibility and coordination of dramatic change, and communication of vision and change.

In the final chapter, Chapter 22, Levine concludes our work by reflecting on the experiences and contributions from the software agility movement. This paper identifies on that background the key challenges and dilemmas involved in agile software practices and goes on to discuss how to further develop this software development paradigm.

After Chapter 22, we have completed the book by including the descriptions of three panels that were part of the IFIP working conference that drove the creation of this book. Although it was impossible to include full transcripts of the panel discussion, the insights into the discourse developed by the panelists are, at least partly, revealed.

The six parts of the book, and the 22 chapters collectively explore the motivation for a study of business agility and IT diffusion, the four major aspects of business agility, and the challenges before us. In a world in which change and uncertainty drive the needs for business agility, and digital information drives business, agility in IT is critical for business success. We believe it is important to understand how IT agility, and thereby business agility, is multifaceted: composed of agile IT diffusion, IT infrastructure agility, and agile IT development. In the 21 chapters that follow, you will learn how, these facets can together provide a concerted pathway to business agility.

\section{REFERENCES}

Aoyama, M. "Web-Based Agile Software Development," IEEE Software (15:6), 1998, pp. 5565.

Cockburn, A. Agile Software Development, Reading, MA: Addison-Wesley, 2001.

Hoffman, T. "Outsourcing Debate Driven by Cost, Agility," Computerworld (37:9), 2003, p. 14.

Kidd, P. T. Agile Manufacturing, Forging New Frontiers, London: Addison-Wesley, 1995.

Leidner, D., Beatty, R., and Mackay, J. "How CIOs Manage IT During Economic Decline: Surviving And Thriving Amid Uncertainty," MISQ Executive, (2:1), 2003, pp. 1-14.

Morgan, R. E. "Business Agility and Internal Marketing," European Business Review (16:5), 2004, pp. 464-472.

Pries-Heje, J., Baskerville, R., Levine, L., and Ramesh, B. "The High Speed Balancing Game," Scandinavian Journal of Information Systems (16), 2004, pp. 1-46.

Sharifi, H., and Zhang, Z. "Agile Manufacturing in Practice: Application of a Methodology," International Journal of Operations and Production Management (21:5/6), 2001, pp. 772794.

\section{ABOUT THE AUTHORS}

Richard L. Baskerville is professor and chairman of the Computer Information System Department at Georgia State University. His research and authored works regard security of information systems, methods of information systems design and development, and the interaction of information systems and organizations. Richard is the author of Designing Information Systems Security (J. Wiley) and more than 100 articles in scholarly journals, 
practitioner magazines, and edited books. He is an editor of The European Journal of Information Systems, and associated with the editorial boards of The Information Systems Journal and The Journal of Database Management. He is a Chartered Engineer, holds a B.S. summa cum laude, from The University of Maryland, and the M.Sc. and Ph.D. degrees from The London School of Economics. Richard can be reached at baskerville@acm.org.

Jan Pries-Heje is an associate professor at the IT University of Copenhagen, Denmark. Jan holds M.Sc. and Ph.D. degrees from Copenhagen Business School. He is a certified ISO 9000 auditor and Bootstrap assessor, and has been project manager for a number of multi-media and IT-related change projects. From 1997 through 2000, he worked as a consultant in IT quality and software process improvement. He is chairman of the Information Systems Research in Scandinavia (IRIS) Steering Committee, serves as the Danish National Representative to IFIP TC8 (since 1999), and is currently an associate editor for MIS Quarterly, Information Systems Journal, and European Journal of Information Systems. His research interests include information systems development, software engineering, and software process improvement. He focuses on organizational and managerial issues. Jan has published more than 100 papers in these areas in journals and conferences. He can be reached at jpr@itu.dk.

Lars Mathiassen is Georgia Research Alliance Eminent Scholar and Professor in Computer Information Systems at Georgia State University. His research interests focus on engineering and management of IT systems. In particular, he has worked with project management, objectorientation, organizational development, management of IT, and the philosophy of computing. Lars can be reached at Imathiassen@gsu.edu. 